\title{
The Effect of Service Quality and Medical Environment Towards Patients' Satisfaction in the Medical Industry in China
}

\author{
Mandy Mok Kim Man ${ }^{1} \&$ Yace Chen ${ }^{2}$ \\ ${ }^{1}$ University of Reading Malaysia, Malaysia \\ ${ }^{2}$ Nilai University, Malaysia \\ Correspondence: Mandy Mok Kim Man, University of Reading Malaysia, Malaysia. E-mail: \\ sa919676@reading.ac.uk
}

Received: March 5, 2020 Accepted: April 14, 2020 Online Published: April 27, 2020

doi:10.5539/ijms.v12n2p72 URL: https://doi.org/10.5539/ijms.v12n2p72

\begin{abstract}
In recent years, the medical and health system face the stern competition of medical market and patients have more choices to choose the medical services that they want. Improving patients' satisfaction has become the overall development of hospitals and it is one of the important contents to increase the competitiveness of the markets. This paper provides a further understanding about patient satisfaction by examining the determinants of patients' satisfaction in the medical industry in China. Service quality and quality of medical environment were tested towards patients' satisfaction. The results show that quality of service and medical environment have significant positive impacts on patient satisfaction.
\end{abstract}

Keyword: patient satisfaction, service quality, medical environment, medical industry

\section{Introduction}

Medical services consumption is basic human needs, which have obvious characteristics of rigid demand (Jung \& Tran, 2014). Medical services consumption is often priority to be satisfied when the residents' income is increased. The government and private sectors attach great importance to the development of medical service, which gradually increases financial input to the medical industry (Chai, Xing, \& Yang, 2016). Medical service industry is developing rapidly, with the support and involvement of both sectors.

China is a country with the largest population in the world. Due to the per capita average life expectancy has increased and the growth of the GDP per capita, people put more and more investment on health, so health service demand also will be increased (Long, Xu, \& Bekedam, 2013). According to the survey the total health expenses reached one trillion Yuan for the first time in 2007 and it increased one trillion seven hundred billion Yuan in 2009. However, total health cost is just only 14.32 billion Yuan in 1980 in China. Through compared from 1980 to 2009 , the compound annual growth rate is $17.95 \%$ on the medical services consumption (Atella, Brugiavini, \& Pace, 2015). The total health expenses accounting for the proportion of Gross Domestic Product (GDP) had increased up to $5.13 \%$ in 2009 . The recent statistics show that in 2018, the total expenditure on health care in China reached over 5.9 trillion yuan (Lai, 2020).

Due to population growth, the prolongation of life and the improvement in people's income level, people widely considered that the main driving force of the development is medical service industry (Imison, Castle-Clarke, $\&$ Watson, 2016). Therefore, improving patients' satisfaction on medical service industry has played a great role in promoting and provides a good space for development (Tsai, Orav, \& Jha, 2015).

Patient satisfaction refers to people who have expectations on health care services based on health, disease, quality of life requirements, which is a kind of evaluation on the experience of health care services (Matsuda, Kawahara, \& Okazaki, 2013). It is a kind of emotional state after comparing expectations and experience of health care services.

This paper presents the background and overview in the first section. The second section presents the research framework. In the third section, research methodology and methods for data analysis are presented. As for the fourth section, results for data analysis are presented and discussion about the outcome. The last fifth section provides the conclusion for the study. 


\section{Objectives}

Medical services are often understood as technical services, excluded emotional services, cultural services and spirit of service (Kangovi, Barg, \& Carter, 2013). They thought that service object was only as the treatment of diseases and patients needed only medical technology. Therefore, they had ignored the inner emotions of the patients (Cottrell, O'Brien, \& Curry, 2014). They did not aware that by increasing patient satisfaction can lead to higher profit return (Lupton, 2014).

Therefore, the hospitals need to constantly improve the service quality and perfect service system. With attractive services and the positive attitude of all hospital staff for the patients, this can improve the patient satisfaction (Higgins, 2015). At the same time, the opinions of the patients could be properly transferred to practical and implementation of strategy for solutions. In this regard, the research objective is to examine how service quality and medical environment can influence patient satisfaction in the medical industry in China.

\section{Literature Review}

The following section reviews the three main variables for this present study.

\subsection{Service Quality}

Quality of medical care service is the first element of market competition (Amin \& Zahora, 2013). Not only it directly related to patient safety and outcomes, and it is also a prerequisite for the survival of the hospital. Hospital should continue to improve the quality of hospital services. Service quality assessment and management have become a core focus of medical services (Amin \& Zahora, 2013). In the "patient-centered" concept of medical services, patients should be given the right to participate in the evaluation of the quality of medical services.

Patients' satisfactions with the quality of medical services are important indicator of the quality of health care evaluation. With the health system reform and health care increasingly fierce competitive environment, hospitals have varying degrees of enhanced patient satisfaction investigation and devoted attention.

Medical quality is not only directly related to patient safety, it is a prerequisite for the survival of the patient, but it is also related to the survival of the hospital, medical quality is the core focus of the work of quality medical institutions (Manary, Boulding, \& Staelin, 2013). China's aging population has sharp increase in consumption of health resources, people's living standard has improved, the quality of medical services has become increasingly demanding. As a result of the new technology and new equipment references, the medical services have increased drastically. It has affected people's satisfaction on the quality of medical services.

\subsection{Medical Environment}

The quality of medical environment is closely related to each family (Jongerden, Slooter, \& Peelen, 2013). Enhance feelings is eagerly anticipated by all citizens. For a long time, municipal hospitals and city hospitals have a large number of high-quality medical resources and this has caused many patients to go to these hospitals for medical treatments. This made municipal hospitals overcrowded (Kirwan, Matthews, \& Scott, 2013). Hospital space design should not only emphasize on its function and ignore the function of its aesthetic, spiritual, and ecology. Therefore, people had put forward the concept of "medical environment". This concept emphasizes the design of medical environment and reflect "people-oriented" concept of humanized design.

Hospital is a place where people's life and health entrusted there (Chang, Chen, \& Lan, 2013). Hospital is also a community for medical staff and patients when patients go to the hospital with pain. Hospital should give patients, staff and visitors a clean and comfortable environment, a convenient and humanized process, a warm and sincere communication, whose are the best ways to improve patient satisfaction.

\subsection{Patient's Satisfaction}

Patients' satisfaction refers to people have some expectations on health care services based on health, disease, quality of life requirements, which is a kind of evaluation on the experience of health care services (Chang et al., 2013). It is a kind of emotional state after comparing expectations and experience of health care services. According to Abdelhak and Rhia (2016), patients will evaluate before accepting the medical service expectations and finally received. Patients' satisfactions have important influence on the survival for medical service and development of the hospital. The reason is satisfied patients will be the loyal customers for the hospital services (Lyu, Wick, \& Housman, 2013). Patients will consider whether the service quality of medical institutions meet or exceed their expectations. Patients' satisfaction will influence the goodwill of a hospital. If patients are satisfied with services in the hospital, they will recommend this hospital to their friends or relatives and will say something good about the hospital. This indirectly will attract more patients to come to this hospital. 


\section{Concept Theory Framework}

Quality of medical services is important to improve the people's health, but it also reflects the medical diagnosis and treatment techniques of medical services, the level of management, as well as a comprehensive reflection on medical ethics, which is the key to survival and development for hospital (Kitapci, Akdogan, \& Dortyol, 2014). Therefore, hospitals will improve medical quality as the first priority. Previous research had shown that the quality of hospital services determined the patient satisfaction (Wong, Coulter, \& Hewitson, 2015; Aliman \& Mohamad, 2013; You, Aiken, \& Sloane, 2013).

With the development of times and the improvement of people's living standards, the function of the medical treatment building is no longer just remained as curing diseases (Djukic, Kovner, \& Brewer, 2013). People have proposed higher request for medical environment (Jongerden et al., 2013). The creation of humanized hospital environment problem has gradually received wide attention from all walks of life (Chang et al., 2013).

Based on the above literature review, the following research framework is developed.

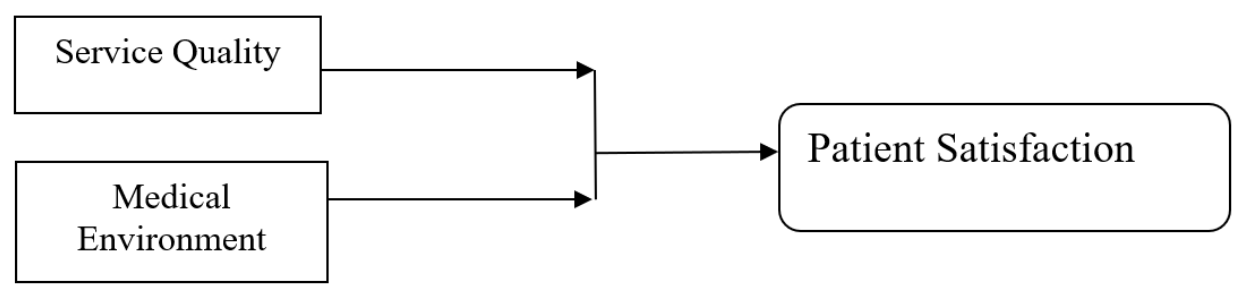

Figure 1. Research framework

Two hypotheses were derived from the research framework as follows:

Hypothesis 1: Service Quality has significant positive influence on patient's satisfaction in medical industry in China.

Hypothesis 2: Quality of medical environment has significant positive influence on patient's satisfaction in medical industry in China.

\section{Materials and Methods}

The present study applied quantitative method by using questionnaires to collect data from the respondents. The questionnaires were design based on the published research questions in high impact factor journals which have been tested for their reliability and validity. Data were collected from 200 patients from the 25 hospitals in China. The first section of the questionnaires asked about respondents' demographic data (e.g., age, gender, education level and income level). The second section of the questionnaires asked respondents to give the rating to the questions. Five questions asked about service quality in hospitals. There are also five questions about medical environment and another four questions asked about patient's satisfaction. The questionnaires were distributed to respondents through emails and mails and followed up with phone calls, phone messages and face-to-face interviews. Using stratified sampling technique, the patients were randomly selected. The data were tested for reliability and validity, which included Q-Q plots and auto-correlations, followed by factor analysis, correlation analysis and regression analysis using Statistical Package of Social Sciences (SPSS) software.

The next section presents the results for the tests mentioned above.

\section{Results}

Reliability and validity test and factor analysis were conducted. Table 1 presents the reliability and validity tests and Table 2 presents the factor analysis.

Table 1. Reliability and validity test

\begin{tabular}{lll}
\hline Variable & Coronach $\alpha$ coefficient & No. of Items \\
\hline Service Quality & .896 & 5 \\
Medical Environment & .899 & 5 \\
Patient's Satisfaction & .833 & 4 \\
\hline
\end{tabular}


The test shows that the Coronach $\alpha$ coefficient is above 0.80 , which is good. This confirmed that the items are reliable and valid.

Table 2. Factor analysis

\begin{tabular}{|c|c|c|c|}
\hline \multirow[t]{2}{*}{ Variables } & \multicolumn{3}{|c|}{ Factor Loading } \\
\hline & 1 & 2 & 3 \\
\hline \multicolumn{4}{|l|}{ Service Quality } \\
\hline -degree of registered time is moderated & 0.629 & & \\
\hline -good service attitude & 0.648 & & \\
\hline -clear communication and service content & 0.638 & & \\
\hline -broad humanistic service content & 0.617 & & \\
\hline -doctors with patience to solve problems & 0.665 & & \\
\hline \multicolumn{4}{|l|}{ Medical Environment } \\
\hline -hospital marking guides are humanization & & 0.557 & \\
\hline -don't have obviously noisy voice & & 0.583 & \\
\hline -floor, corridors and bath lavatory are clean & & 0.591 & \\
\hline -security facilities are good & & 0.572 & \\
\hline -sickroom air adjusting is comfortable & & 0.564 & \\
\hline \multicolumn{4}{|l|}{ Patients Satisfaction } \\
\hline -satisfaction depends on overall environment & & & 0.631 \\
\hline -well-known hospital makes patients satisfied & & & 0.572 \\
\hline -friend recommended hospital makes patients satisfied & & & 0.564 \\
\hline -reasonable price makes patients satisfied & & & 0.655 \\
\hline
\end{tabular}

The items loaded in three components with above 0.5 . This meant that the items with the right variables loading on each factor, confirming that the main variables have been measured correctly. Table 3 shows the regression analyses.

Table 3. Regression analyses

\begin{tabular}{|c|c|c|c|c|c|c|c|c|c|}
\hline \multirow[t]{2}{*}{ Model } & \multirow[t]{2}{*}{$\mathrm{R}$} & \multirow[t]{2}{*}{ R Square } & \multirow[t]{2}{*}{ Adjusted R Square } & \multirow[t]{2}{*}{ Std. Error of the Estimate } & \multicolumn{5}{|l|}{ Change Statistics } \\
\hline & & & & & R Square Change & F Change & df1 & $\mathrm{df} 2$ & Sig. F Change \\
\hline 1 & $.964^{\mathrm{a}}$ & .086 & .063 & .91324 & .086 & 3.672 & 5 & 194 & .001 \\
\hline 2 & $.944^{\mathrm{b}}$ & .965 & .963 & .18173 & .878 & 1177.305 & 4 & 190 & .031 \\
\hline
\end{tabular}

The results show that there is significant correlation between service quality and medical environment towards patient's satisfaction. The findings show that the service quality and patient's satisfaction was significantly positively related $(r=0.964, \mathrm{p}<0.01)$ and the medical environment and patient's satisfaction was significantly positively related $(\mathrm{r}=0.944, \mathrm{p}<0.01)$. The figures obtained are above 0.9 , that mean these variables (independent variables) are strongly significant with the dependent variable (patient's satisfaction). Therefore, when these independent variables increased, the patient's satisfaction is also increased. Hypothesis 1 and 2 are supported. Table 4 shows the summary of hypotheses testing.

Table 4. Result of hypothesis testing

\begin{tabular}{lll}
\hline Hypothesis & Significant & Decision \\
\hline $\begin{array}{l}\text { H1: Service Quality has significant positive influence on patient's satisfaction in medical } \\
\text { industry in China. }\end{array}$ & $.001^{* *}$ & Supported \\
$\begin{array}{l}\text { H2: Medical Environment has significant positive influence on patient's satisfaction in medical } \\
\text { industry in China. }\end{array}$ & $.031^{*}$ & Supported
\end{tabular}

Note. Significant at the level of: $* \mathrm{p}<0.05,{ }^{* *} \mathrm{p}<0.01,{ }^{* * *} \mathrm{p}<0.001$.

\section{Conclusions and Discussion}

This study analyses the factors that affected patient's satisfaction in medical industry in China. The findings show that service quality and medical environment influence patients' satisfaction. The hospitals need to develop strategies that improve these aspects in order to maintain the current market and at the same time to attract more 
patients to their hospitals.

Patients expect that their problems will be listened and actions will be taken to solve their problems. Among the problems faced by patients are lacking of privacy space for them, high medical bills for the consultations, late responses from the hospitals about their diseases. In the rapidly changing markets, the hospitals need to listen to patients and solve their problems. For example, hospitals set up some special consultation services according to the requirements of patients with reasonable prices, setting more space for patients for their privacy, immediate responses for emergencies and provide a more conducive environment for patients. This will reduce patients' complaints and increase their satisfaction.

In conclusion, service quality and medical environment influence patients' satisfaction in medical industry in China. The findings congruent with previous study of Kitapci et al. (2014) stated that service quality leads to patients' satisfaction and Kirwan et al.'s (2013) study mentioned that clean, systematic, high quality medical environment increased patients' satisfaction.

This study inspects hospitals' service quality form the patient's perspective. The findings from this study could be applied for drawing new development strategies for hospitals. Hospitals are recommended that to solve the patients' complaints and also the problems faced in operations and administrations to meet the high standard of medical industry internationally.

\section{References}

Abdelhak, M., \& Rhia, F. (2016). Patient Engagement: Opportunities and Challenges for Nursing and Health Care Professionals. Nursing Informatics, 707-721.

Aliman, N. K., \& Mohamad, W. N. (2013). Perceptions of Service Quality and Behavioral Intentions: A Mediation Effect of Patient Satisfaction in the Private Health Care in Malaysia. International Journal of Marketing Studies, 5(4), 15-24. https://doi.org/10.5539/ijms.v5n4p15

Amin, M., \& Zahora, N. S. (2013). Hospital Service Quality and Its Effects on Patient Satisfaction and Behavioural Intention. Clinical Governance: An International Journal, 18(3), 238-254. https://doi.org/10.1108/CGIJ-05-2012-0016

Atella, V., Brugiavini, A., \& Pace, N. (2015). The Health Care System Reform in China: Effects on Out-of-Pocket Expenses and Saving China. Economic Review, 34, 182-195. https://doi.org/10.1016/j.chieco.2015.02.003

Chai, J., Xing, L., \& Yang, Y. (2016). Does Medical Insurance Improve Household Consumption in China?-A Re-analysis Based on Meta Regression Analysis. Journal of Systems Science and Information, 4(3), 235-243. https://doi.org/10.21078/JSSI-2016-235-09

Chang, C. S., Chen, S. Y., \& Lan, Y. T. (2013). Service Quality, Trust and Patient Satisfaction in Interpersonal-based Medical Service Encounters. BMC Health Services Research, 13(1), 1-6. https://doi.org/10.1186/1472-6963-13-22

Cottrell, E. K., O’Brien, K., \& Curry, M. (2014). Understanding Safety in Pre-hospital Emergency Medical Services for Children. Prehospital Emergency Care, 18(3), 350-358. https://doi.org/10.3109/10903127.2013.869640

Djukic, M., Kovner, C. T., \& Brewer, C. S. (2013). Work Environment Factors Other Than Staffing Associated with Nurses' Ratings of Patient Care Quality. Health Care Management Review, 38(2), 105-114. https://doi.org/10.1097/HMR.0b013e3182388cc3

Higgins, E. A. (2015). The Influence of Nurse Manager Transformational Leadership on Nurse and Patient Outcomes: Mediating Effects of Supportive Practice Environments, Organizational Citizenship Behaviours. Patient Safety Culture and Nurse Job Satisfaction, 37(3), 93-98.

Imison, C., Castle-Clarke, S., \& Watson, R. (2016). Reshaping the Workforce to Deliver the Care Patients Need. Research Report. Nuffield Trust. Retrieved on 17 April, 2020, from https://www.nuffieldtrust.org.uk/files/2017-01/reshaping-the-workforce-web-final.pdf

Jongerden, I. P., Slooter, A. J., \& Peelen, L. M. (2013). Effect of intensive care environment on family and patient satisfaction: a before-after study. Intensive Care Medicine, 39(9), 1626-1634. https://doi.org/10.1007/s00134-013-2966-0

Jung, J., \& Chung, T. (2014). Medical Consumption Over the Life-cycle. Empirical Economics, 47(3), 927-957. https://doi.org/10.1007/s00181-013-0774-6

Kangovi, S., Barg, F. K., \& Carter, T. (2013). Understanding Why Patients of Low Socioeconomic Status Prefer 
Hospitals Over Ambulatory Care. Health Affairs, 32(7), 1196-1203. https://doi.org/10.1377/hlthaff.2012.0825

Kirwan, M., Matthews, A., \& Scott, P. A. (2013). The Impact of the Work Environment of Nurses on Patient Safety Outcomes: A Multi-level Modelling Approach. International Journal of Nursing Studies, 50(2), 253-263. https://doi.org/10.1016/j.ijnurstu.2012.08.020

Kitapci, O., Akdogan, C., \& Dortyol, İ. T. (2014). The Impact of Service Quality Dimensions on Patient Satisfaction, Repurchase Intentions and Word-of-Mouth Communication in the Public Healthcare Industry. Procedia-Social and Behavioral Sciences, 148, 161-169. https://doi.org/10.1016/j.sbspro.2014.07.030

Lai, L. T. (2020). Health expenditure in China 2000-2018. Retrieved on 13 April, 2020, from https://www.statista.com/statistics/279400/health-expenditures-in-china/

Long, Q., Xu, L., \& Bekedam, H. (2013). Changes in Health Expenditures in China in 2000s: Has the Health System Reform Improved Affordability? International Journal for Equity in Health, 12(1). https://doi.org/10.1186/1475-9276-12-40

Lupton, D. (2014). The Commodification of Patient Opinion: The Digital Patient Experience Economy in the Age of Big Data. Sociology of Health \& Illness, 36(6), 856-869. https://doi.org/10.1111/1467-9566.12109

Lyu, H., Wick, E. C., \& Housman, M. (2013). Patient Satisfaction as a Possible Indicator of Quality Surgical Care. JAMA Surgery, 148(4), 362-367. https://doi.org/10.1001/2013.jamasurg.270

Manary, M. P., Boulding, W., \& Staelin, R. (2013). The Patient Experience and Health Outcomes. New England Journal of Medicine, 368(3), 201-203. https://doi.org/10.1056/NEJMp1211775

Matsuda, S., Kawahara, S., \& Okazaki, K. (2013). Postoperative Alignment and ROM Affect Patient Satisfaction After TKA. Clinical Orthopaedics and Related Research, 471(1), 127-133. https://doi.org/10.1007/s11999-012-2533-y

Tsai, T. C., Oray, E. J., \& Jha, A. K. (2015). Patient Satisfaction and Quality of Surgical Care in US Hopsitals. Annals of Surgery, 261(1), 2. https://doi.org/10.1097/SLA.0000000000000765

Wong, E. L. Y., Coulter, A., \& Hewitson, P. (2015). Patient Experience and Satisfaction with Inpatient Service: Development of Short Form Survey Instrument Measuring the Core Aspect of Inpatient Experience. PloS One, 10(4), 12-25. https://doi.org/10.1371/journal.pone.0122299

You, L., Aiken, L. H., \& Sloane, D. M. (2013). Hospital Nursing, Care Quality and Patient in Hospital in China and Europe. International Journal of Nursing Studies, 50(2), 154-161. https://doi.org/10.1016/j.ijnurstu.2012.05.003

\section{Copyrights}

Copyright for this article is retained by the author, with first publication rights granted to the journal.

This is an open-access article distributed under the terms and conditions of the Creative Commons Attribution license (http://creativecommons.org/licenses/by/4.0/). 